\title{
Body Integrity Identity Disorder: Development and Evaluation of an Inventory for the Assessment of the Severity
}

\author{
Mona L. Fischer ${ }^{2}$, Thomas Schnell ${ }^{1}$, Erich Kasten ${ }^{2}$ \\ ${ }^{1}$ Dept. of Clinical Psychology, Medical School Hamburg, University of Applied Sciences, Am Kaiserkai 1, Hamburg, Germany \\ ${ }^{2}$ Dept. of Neuropsychology, Medical School Hamburg, University of Applied Sciences, Am Kaiserkai 1, Hamburg, Germany
}

\author{
Email address: \\ Mona.Fischer@studium.uni-hamburg.de (M. L. Fischer), EriKasten@aol.com (E. Kasten), \\ thomas.schnell@medicalschool-hamburg.de (T. Schnell)
}

\section{To cite this article:}

Mona L. Fischer, Thomas Schnell, Erich Kasten. Body Integrity Identity Disorder: Development and Evaluation of an Inventory for the Assessment of the Severity. American Journal of Applied Psychology. Vol. 4, No. 3, 2015, pp. 76-82. doi: 10.11648/j.ajap.20150403.15

\begin{abstract}
Body Integrity Identity Disorder (BIID), the wish of subjects for an amputation of otherwise healthy limbs, is a rare disturbance. Until now, BIID was seen as a symptom affecting a group of people suffering from an urging desire for amputation. But while some of the BIID-affected people only have a weak wish for an amputation others show severe symptoms. The aim of this work was the development of a psychological test to measure the severity of the wish for amputation or palsy in BIID afflicted subjects. Additionally, we analyzed correlation with demographic data. We developed a survey in English and German language from which three pairs of similar items were created for a test of reliability. 45 people affected by BIID answered this survey ( 38 men, 7 women, age $42.6 \pm 12.4$ ). After controlling for robustness, a normal distribution of the "BIID-severity" could be detected and the subjects were divided into 5 groups ( $<2 \mathrm{SD}$ : very low, -2 to $-1 \mathrm{SD}$ : light, -1 to +1 SD: moderate, +1 to $+2 \mathrm{SD}$ : heavy, > +2 SD: very heavy BIID). The severity of BIID sufferers was not more pronounced in older than in younger subjects, but BIID affects more men than women and the first manifestation of BIID occurs predominantly in childhood.
\end{abstract}

Keywords: Body Integrity Identity Disorder, BIID, Apotemnophilia, Xenomelia, Amputee Identity Disorder

\section{Introduction}

To the general public, Body Integrity Identity Disorder is a largely unknown disorder. Sufferers feel an intensive desire for a physical disability and it is the opinion of these people that only an amputation or palsy can bring their real body in line with the subjectively perceived "right" mental body scheme $[9,21]$. Beginning in their childhood, sufferers have an intensive feeling that a healthy limb does not belong to their body. In most cases the target is a leg, but other limbs can be affected as well. Most commonly, the desire for amputation is below the left thigh, followed in frequency by a right and bilateral leg amputation [13].

In some individuals the unwanted part of the body changes over time, often for purely pragmatic reasons, such as for example to continue driving [14].

The proportion of those who feel sexual arousal at the idea of being self-amputated is estimated to be $2 / 3$, but in about $75 \%$ of these the sexual aspect has no priority $[9,15,11]$. Almost all affected subjects show a kind of substitute behavior: pretending refers to faking the desired physical disability, e.g. the use of crutches or a wheelchair. The pretending behavior not only causes feelings of happiness and can bring relief, it is also useful to find out problems of the desired amputation or plegia in activities of daily living [15].

The BIID afflicted people identify themselves as "Wannabe" (from "want to be"), other names for the strange urge are: "apotemnophilia", "amputee identity disorder", "Xenomelia" or "Body Incongruence Disorder" [see e.g. 19, 2, 4, 18]. Until now, no diagnostic criteria exist for the classification of this disorder neither in the ICD-10 nor in the DSM-V. The onset is usually in childhood, often post-pubertal. Almost all BIID subjects report a key-event: When they have watched somebody with a handicap (e.g. a wheelchair user or peg-legged man), they felt a fascination for this kind of "otherness". This experience triggers the development to become an amputee. The desire has a persistent character, but is often associated with shame and guilt [24].

So far, no psychotherapeutic or pharmacological therapy is known. Neither cognitive-behavioral nor psychodynamic 
therapy nor administration of antidepressants have shown satisfactory results, however, they can lead in some cases to a reduction of psychological stress from the desire [4, 25]. Based on a study of 20 people who have successfully reached the desired amputation, it is supposed that a total disappearance of the suffering is possible only after an amputation of the limb [21].

Until now, BIID was seen as symptom affecting people strongly as they suffer heavily from an urging desire for amputation. But from personal talks the authors learned that some of the BIID patients only have a weak wish for an amputation and were able to cope with this feeling without specific plans for an operation. The classification of the severity of BIID is an important question for future research. Therefore the main task of this work was the development of a psychological test to measure the strength of the wish for amputation or palsy in BIID afflicted subjects. Additionally this study investigated gender differences regarding the severity of BIID.

\section{Method}

\subsection{Participants and Design}

For recruiting participants, a link on a BIID website was published (www.biid-dach.org). The screening instrument aimed exclusively at BIID sufferers. Exclusion criteria were the presence of other diseases (e.g. schizophrenia, body dimorphic disorder). The questionnaire was not directed at sufferers who have already achieved their physical disability due to a surgical procedure. Because of an incomplete number of responses ( $>20 \%$ missing items), the data of one subject were excluded from further analysis. BIID is an extremely rare disorder. Until now, the world's largest study included 52 subjects [9]. In our study the data of 45 subjects were analyzed. For the norming procedure of a new test, this is a very small number. However, it was not possible to get a larger sample. The distribution of the demographic data of the sample is shown in Table 1.

Table 1. Demographic data.

\begin{tabular}{ll}
\hline Criterion & Sample $(\mathbf{n}=\mathbf{4 5})$ \\
\hline Male /female & $38 / 7$ \\
Age (years) & $42,6(\mathrm{SD}=12,38)$ \\
Sexual orientation & \\
Heterosexual & $37(82,2 \%)$ \\
Homosexual & $8(17,8 \%)$ \\
Bisexual & $0(0 \%)$ \\
Marital status & \\
Single & $22(48,9 \%)$ \\
Divorced & $17(37,8 \%)$ \\
Married & $5(11,1 \%)$ \\
Widowed & $1(2,2 \%)$ \\
Education level in years & 16,1 \\
\hline
\end{tabular}

\subsection{Instruments}

The severity of BIID was investigated with a questionnaire, based on the existing literature. Demographic data (age, gender, sexual orientation, education level in years, current occupation, and marital status) are recorded at the beginning of the questionnaire (items 1-8). Then questions are asked (a) for the last six months and (b) the last 14 days to analyze both, habitual and current feelings and behaviors. The participants have the option of applying their statements on a 7-point Likert-scale from strongly disagree to strongly agree. For the investigation of the duration of individual BIID-thoughts and behaviors we used open answers. The screening questionnaire is currently available in a German and an English version.

\section{Results}

\subsection{Statistical Analysis}

For an analysis of this test's reliability three pairs of items with very similar content were asked in different parts of the questionnaire (Item 12/23, Item 15/25, Item 19/32). These pairs must have a high correlation to ensure that the questionnaire was filled out reliably. Statistical analysis was made with SPSS. The open questions (item 9; Item 34-38) were transformed into categories to allow statistical analysis. The survey period for this study began in January 2013 and ended in April 2013.

The criterion of objectivity of this psychological test can be considered as given. Using an online-questionnaire, questions and answers are independent of the examiner and the situation; analysis and interpretation of the statements underlie a standardized instruction.

To increase the test-selectivity, 7 items with a correlation $<.3$ with the total-test-score were removed. After elimination of these non-sharp items, Cronbach's Alpha rose from .866 to .929 and is therefore in the excellent range. The corrected discriminatory powers of the items were between .338 and .760 .

Hereafter, the items 14 - 31 were summarized and divided through the number of test items to give a total-test-score for the severity of the BIID desire. For this purpose, the results of the negative formulated items (No. 14, 15, 22, 24, 26, 27, 31) were reversed. Based on this data analysis a normal distribution of the BIID-severity could be detected (see Figure 1).

\subsection{Severity of BIID}

On a 7-point scale, the average total-test-score "severity" is 4,6. The minimum is 1.5 and the maximum is 6.29 , the variance is $1.16(\mathrm{SD}=1.078)$. The classification of the severity of BIID is based on the calculated standard deviation (see Table 2). Using these classes, it is now possible to use the questionnaire in psychological and psychiatric practice, as well as for future studies. The classification of the severity of BIID is shown in Table 3. The hypothesis about differences between gender showed that men suffer significant stronger than women (see Table 4). 


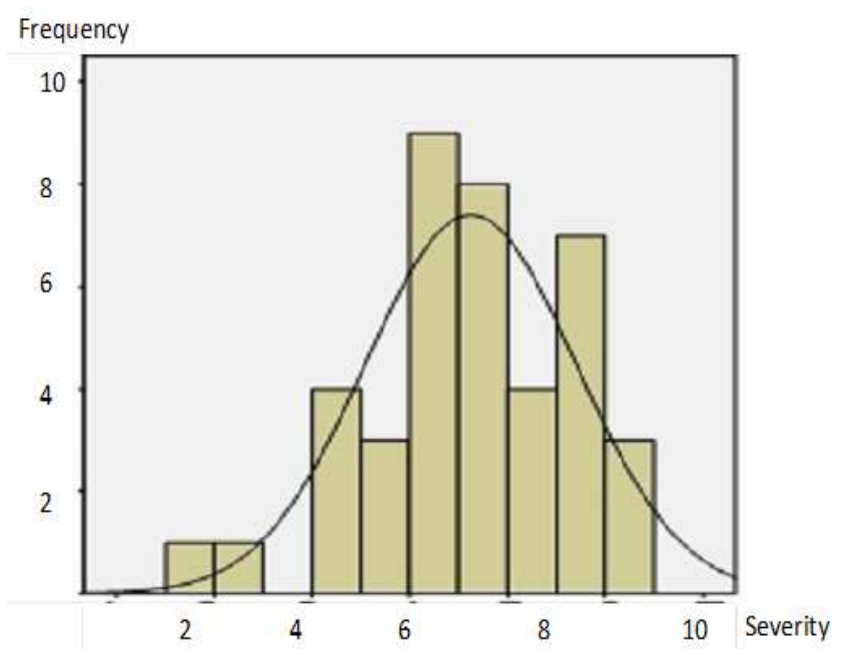

Figure 1. Distribution of BIID-severity. (Y-Axis=frequency; $X$-Axis $=$ severity).

Table 2. Severity of BIID.

\begin{tabular}{ll}
\hline Severity & \\
\hline Mean & 4,6226 \\
Median & 4,7857 \\
Modus & $4,43^{\mathrm{a}}$ \\
Standard Deviation & 1,07768 \\
Variance & 1,161 \\
Minimum & 1,52 \\
Maximum & 6,29 \\
\hline
\end{tabular}

Table 3. Classification of the severity of BIID.

\begin{tabular}{lll}
\hline Severity & Mean Score & Standard Deviation \\
\hline Very mild BIID & $<2,6$ & $<-2$ \\
Mild BIID & $2,6-3.5$ & $-2--1$ \\
Medium BIID & $3,6-5,5$ & $-1-+1$ \\
Severe BIID & $5,6-6,5$ & $+1-+2$ \\
Very severe BIID & $>6,5$ & $>+2$ \\
\hline
\end{tabular}

Table 4. Gender differences in severity of BIID.

\begin{tabular}{llllll}
\hline & sex & n & mean & $\begin{array}{l}\text { Standard } \\
\text { deviation }\end{array}$ & $\begin{array}{l}\text { Standard } \\
\text { deviation of the } \\
\text { mean }\end{array}$ \\
\hline \multirow{2}{*}{ Severity } & men & 33 & 4,5400 & 80217 & 13964 \\
& women & 4 & 3,9554 & 59503 & 29751 \\
\hline
\end{tabular}

\subsection{Quantitative Information}

The open-ended questions at the start of the inventory came to some interesting additions. The results showed a strong erotic component of BIID-participants for a partner with disabilities and/or an own disability. Additionally, three participants mentioned urinary incontinence and four participants stump food as desired disabilities. Obviously, the wish for amputation or palsy is not the only disabilities which aim BIID sufferers. An interesting research question could be, which physical changes can be subsume under BIID? The questions No. 10-13 showed that BIID sufferers spend mostly every day thinking about BIID related surgery. Nevertheless, only three participants spend regularly time on planning with which method they can cause the desired disabilities themselves. Most subjects seem to suffer a lot, though, illegal amputations or self-mutilation are mostly not an option. Pretending the desired disability as often as possible is the most frequently mentioned coping strategy.

\section{Limitation}

There are a few limitations to name, which might restrict the significance of this study. Due to the small sample size of $\mathrm{n}$ $=45$, these are only preliminary normative data. This factor affects the reliability and external validity of the findings. For the norming procedure of a new test, this is a very small number. However, it was not possible to get a larger sample. It is necessary to evaluate the inventory on a larger sample in further investigations. Moreover, the link to the survey was put online on specific BIID websites. Therefore, it is possible that the sample consists of people, who suffers more than affected who don't visit such specific BIID websites. Further the participants of this survey consisted of 38 men and only 7 women. This imbalance could be a characteristic of the disease or due to the internet-based recruitment. Internet-based questionnaires have the advantage of allowing the investigation of large groups of people even if the condition of interest is very rare. However, the internet also permits anonymous participation and in general it is easier to reach men than women.

\section{Conclusion}

The main aim of this work was the development of a psychological test to measure the strength of the wish for amputation or palsy in BIID afflicted subjects. Additionally this study investigated gender differences regarding the severity of BIID. The severity of BIID was investigated with a questionnaire, based on the existing literature. The classification of the severity of BIID is based on the calculated standard deviation. Using these classes, it is now possible to use the questionnaire in psychological and psychiatric practice, as well as for future studies. For the norming procedure of a new test, $n=45$ is a very small number. It is necessary to evaluate the inventory on a larger sample in further investigations to insure a higher reliability and external validity of the findings. Additionally, we analyzed correlation with demographic data. The severity of BIID sufferers was not more pronounced in older than in younger subjects, but BIID affects more men than women and the first manifestation of BIID occurs predominantly in childhood. These results are in line with previous investigations about BIID. 


\section{Body Integrity Identity Disorder:}

\section{Instructions for the Assessment of the Severity}

The BIID Inventory contains 32 questions. Demographic data (age, gender, sexual orientation, education level in years, current occupation, and marital status) are recorded at the beginning of the questionnaire (items 1-9). Then questions are asked (a) for the last 14 days and (b) for the last six months to analyze both, habitual and current feelings and behaviors. The participants have the option of applying their statements on a 7-point Likert-scale from strongly disagree to strongly agree. For the investigation of the duration of individual BIID-thoughts and behaviors we used open answers. For the assessment of the severity the scores of items 14-31 were summarized and divided through 18 to give a total score for the severity. For this purpose, the results of the negative formulated items (No. 14, 15, 22, 24, 26, 27, 31) were reversed. Higher scores indicate more severe symptoms of BIID.

Tab. 6. The standardized cut-offs:

\begin{tabular}{lll}
\hline Severity & Mean Score & Standard Deviation \\
\hline Very mild BIID & $<2,6$ & $<-2$ \\
Mild BIID & 2,6 to 3,5 & -2 to- 1 \\
Medium BIID & 3,6 to 5,5 & -1 to +1 \\
Severe BIID & 5,6 to 6,5 & +1 to +2 \\
Very severe BIID & $>6,5$ & $>2$ \\
\hline
\end{tabular}

Items 16, 17, 18, 19, 20, 21, 23, 25, 28, 29, 30:

Strongly disagree $=1$

Disagree $=2$

Rather agree $=3$

It depends $=4$

Rather agree $=5$

Agree $=6$

Strongly agree $=7$

Items 14, 15, 22, 24, 26, 27, 31:

Strongly disagree $=7$

Disagree $=6$

Rather agree $=5$

It depends $=4$

Rather agree $=3$

Agree $=2$

Strongly agree $=1$ 


\section{Body Integrity Identity Disorder - Screening for Severity and Intensity}

This survey is exclusively aimed at subjects suffering from 'Body Integrity Identity Disorder' (BIID). BIID is a clinical picture indicating a long-standing wish for physical disability to align the real body with the image that is considered 'right' by the subject. The following statements serve to assess both the severity and the intensity of your BIID. Please select a level of accuracy for the statement that best describes how you felt during the LAST 14 DAYS (questions 11-13) or the LAST SIX MONTHS (questions 14-31). The scale ranges from 'strongly disagree' to 'strongly agree'. Please mark only one box. There are no 'right' or 'wrong' responses. Therefore, please try to respond spontaneously and quickly.

\section{PERSONAL INFORMATION}

1. Name:

2. Age years

3. Sex
Male
Female

4. Sexual orientation

$$
\begin{aligned}
& \text { heterosexual } \\
& \text { homosexual } \\
& \text { bisexual }
\end{aligned}
$$

5. Years of education (including college and vocational training) years

6. Current profession

\section{Marital status}

Single

Married

Divorced

Widowed
8. I have first noticed being affected by BIID in the age of years.

9. Which body part(s) is/are affected by the desire for amputation/paralysis and how does the physical disability look like? (Please provide a short explanation)

10. How often have you already attempted to do an amputation or a BIID related procedure yourself?

\section{The following questions refer to the LAST 14 DAYS:}

11. On average, how much time had you spend thinking about BIID related surgery?

12. On average, how much time had you spend planning how you can cause the desired disability yourself in the future?

13. On average, how much time had you spend planning with which methods of self-mutilation you can enforce surgery? 


\section{The following questions refer to the LAST 6 MONTHS:}

\begin{tabular}{|c|c|c|c|c|c|c|c|}
\hline Statement & $\begin{array}{l}\text { Strongly } \\
\text { disagree }\end{array}$ & Disagree & $\begin{array}{l}\text { Rather } \\
\text { disagree }\end{array}$ & It depends & Rather agree & Agree & $\begin{array}{c}\text { Strongly } \\
\text { agree }\end{array}$ \\
\hline $\begin{array}{l}\text { Often, I am able to distract myself from BIID to the } \\
\text { extent that I hardly notice it at that moment. }\end{array}$ & $\square$ & $\square$ & $\square$ & $\square$ & $\square$ & $\square$ & $\square$ \\
\hline My daily routine is hardly affected by BIID. & $\square$ & $\square$ & $\square$ & $\square$ & $\square$ & $\square$ & $\square$ \\
\hline I spend a lot of time thinking about BIID related surgery. & $\square$ & $\square$ & $\square$ & $\square$ & $\square$ & $\square$ & $\square$ \\
\hline $\begin{array}{l}\text { I feel distress until undergoing surgery or BIID } \\
\text { disappears in other way. }\end{array}$ & $\square$ & $\square$ & $\square$ & $\square$ & $\square$ & $\square$ & $\square$ \\
\hline I feel affected in my social life by the effects of BIID. & $\square$ & $\square$ & $\square$ & $\square$ & $\square_{5}$ & $\square_{6}$ & $\square$ \\
\hline I perceive my wish for disability to be strong. & $\square$ & $\square$ & $\square$ & $\square$ & $\square_{5}$ & $\square$ & $\square$ \\
\hline I feel affected in my working life by the effects of BIID. & $\square$ & $\square$ & $\square$ & $\square$ & $\square$ & $\square$ & $\square$ \\
\hline $\begin{array}{l}\text { I have already hurt myself or would consider it in order to } \\
\text { enforce surgery. }\end{array}$ & $\square$ & $\square$ & $\square$ & $\square$ & $\square_{5}$ & $\square$ & $\square$ \\
\hline I can continue living without the desired disability. & $\square$ & $\square$ & $\square$ & $\square$ & $\square$ & $\square$ & $\square$ \\
\hline I plan on actually undergoing surgery. & $\square$ & $\square$ & $\square$ & $\square$ & $\square$ & $\square_{6}$ & $\square$ \\
\hline I spend rare time thinking about BIID related surgery. & $\square$ & $\square$ & $\square_{5}$ & $\square$ & $\square$ & $\square$ & $\square$ \\
\hline The wish for BIID related surgery is with me all the time. & $\square$ & $\square$ & $\square$ & $\square$ & $\square_{5}$ & $\square$ & $\square$ \\
\hline I consider my wish for amputation/paralysis to be weak. & $\square$ & $\square$ & $\square$ & $\square$ & $\square$ & $\square$ & $\square$ \\
\hline $\begin{array}{l}\text { I am rarely thinking about which way of self-mutilation } \\
\text { could enforce my surgery. }\end{array}$ & $\square$ & $\square$ & $\square$ & $\square_{4}$ & $\square$ & $\square$ & $\square$ \\
\hline $\begin{array}{l}\text { If I cannot undergo surgery, I consider suicide as a } \\
\text { possible solution. }\end{array}$ & $\square$ & $\square$ & $\square$ & $\square$ & $\square_{5}$ & $\square$ & $\square$ \\
\hline $\begin{array}{l}\text { I often suffer from depression and loss of interest due to } \\
\text { my BIID sickness. }\end{array}$ & $\square$ & $\square$ & $\square$ & $\square$ & $\square$ & $\square$ & $\square$ \\
\hline I would be willing to undergo illegal surgery abroad. & $\square$ & $\square$ & $\square$ & $\square$ & $\square$ & $\square$ & $\square$ \\
\hline $\begin{array}{l}\text { I have not already hurt myself attempting to enforce } \\
\text { surgery and would not consider it. }\end{array}$ & $\square$ & $\square$ & $\square$ & $\square$ & $\square$ & $\square$ & $\square$ \\
\hline
\end{tabular}

Result:

Total Score of items 14-31: $: 18=$ 


\section{References}

[1] Ach, A. \& Pollmann, A. (2006). No body is perfect Baumaßnahmen am menschlichen Körper. Bioethische und ästhetische Aufrisse. Transcript Verlag. Bielefeld.

[2] Bayne, T. \& Levy, N. (2005). Amputees by choice: Body Integrity Identity Disorder and the ethics of amputation. Journal of Applied Psychology, 22, 75-86.

[3] Blanke, O., Morgenthaler, F.D., Brugger, P. \& Overney, L.S. (2009). Preliminary evidence for a fronto-parietal dysfunction in able-bodied particpants with a desire for limp amputation. Journal of Neuropsychology, 3, 181-200.

[4] Braam, A.J., Visser, S., Cath, D.C. \& Hoogendijk, W.J.G. (2006). Investigation of the syndrome of Apotemnophilia and course of a cognitive-behavioral therapy. Psychopathology, 39, 32-37.

[5] Brang, D., McGeoch, P.D. \& Ramachandran, V.S. (2008). Apotemnophilia: a neurological disorder. Neuroreport, 19, 1305-1306.

[6] Brugger, P., Vitacco, D. \& Hilti, L. (2009). A neurological account of Body Integrity Identity Disorder. In: Stirn, Thiel, Oddo (Eds.): Body Integrity Identity Disorder: Psychological, Neurobiological, Ethical and Legal Aspects: 201- 210. Lengerich: Pabst.

[7] Dyer, C. (2000). Surgeon amputated healthy legs. British Medical Journal ,320, 332.

[8] Elliot, C. (2000). A new way to be mad. Amputations sought by healthy people. The Atlantic Monthly, 2866, 73-84. (URL:http:// www.theatlantic.com/ doc/ 200012/ madness; from: 12.11.2012).

[9] First, M.B. (2005). Desire for amputation of a limp: paraphilia, psychosis or a new type of identity disorder. Psychological Medicine,35, 919-928.

[10] First, M.B., Spritzer, R., Gibbon, M. \& Williams, J. (1999). Structured Clinical Interview for DSM-4 Axis 1 Disorders. Biometrics Research Department: New York.

[11] Furth, G. \& Smith, R. (2000). Apotemnophilia Information, questions, answers and recommendations about self-demand amputation. Bloomington: 1stBooks Publishers.

[12] Horn, F. (2003). A life for a limb. Social Work Today, 3, 16-19.

[13] Johnson, A.J., Liew, S.-L. \& Aziz-Zadeh, L. (2011). Demographics, learning and limitation and body scheme in
Body Integrity Identity Disorder. Indiana University Undergraduate Journal of Cognitive Science, 6, 8-15.

[14] Kasten, E. \& Stirn, A. (2009). Wechselnder rechts: links-Amputationswunsch bei Body Integrity Identity Disorder (BIID). Zeitschrift für Psychiatrie, Psychotherapie und Psychologie. 55-61.

[15] Kasten, E. (2009). Body Integrity Identity Disorder (BIID): Interrogation of patients and theories for explanation. Fortschritte der Neurologie-Psychiatrie, 77(1), 16-24.

[16] Kasten, E. (2012). Body Integrity Identity Disorder Körperidentität durch erwünschte Behinderung. Psychiatrie und Psychotherapie. up2date, 6, 165-174.

[17] Kasten, E. \& Spithaler F. (2009). Body Integrity Identity Disorder: Personality Profiles and Investigation of Motives. In: Stirn, Thiel, Oddo (Eds.). Body Integrity Identity Disorder. Papst Science Publishers. P.20-40.

[18] McGeoch, P.D., Brang, D., Song, T., Lee, R.R., Huang, M. \& Ramachandran, V.S. (2010). Xenomelia: a new right parietal lobe syndrome. Journal of Neurology Neurosurgery and Psychiatry, 82, 1314-1319.

[19] Money, J, Jobaris, R. \& Furth, G. (1977). Apotemnophilia: Two cases of self demand amputation as a paraphilia. Journal of Sex Research, 13, 115-124.

[20] Neff, D. \& Kasten, E. (2010). Body Integrity Identity Disorder (BIID): What do health care professionals know? European Journal of Counseling Psychology, 1(2), 16-31.

[21] Noll, S. \& Kasten, E. Body Integrity Identity Disorder (BIID): Body integrity identity disorder (BIID): How satisfied are successful wannabes? Psychology and Behavioral Sciences. 2014; 3(6): 222-232

[22] Ryan, C.J. (2009). Out on Limp: The Ethical Management of Body Integrity Identity Disorder. Neuroethics, 2(1), 21-33.

[23] Sorene, E.D, Heras-Palou, C. \& Burke, F.D. (2006). Self-amputation of a healthy hand: a case of body integrity identity disorder. Journal of Hand Surgery 31, 593-595.

[24] Stirn, A., Thiel, A. \& Oddo, S. (2009). Body Integrity Identity Disorder: Psychological, Neurobiological, Ethical and Legal Aspects. Lengerich: Pabst Verlag.

[25] Thiel, A., Oddo, S., Skoruppa, S., Thiel, J., Ehni, F., Bennett, D \& Stirn, A. (2009). Psychotherapy and Psychometric Research with BIID-Sufferers. In: Stirn, Thiel \& Oddo (Eds.) (2009). Body Integrity Identity Disorder: Psychological, Neurobiological, Ethical and Legal Aspects. Lengerich: Pabst Verlag. P. 58-69. 